4. Cline, M. J., and Melmon, K. L.: Plasma kinins and cortisol: A possible explanation of the anti-inflammatory action of cortisol. Science, 153: 1135 (1966).

5. Cochrane, C. G., Revak, S. D., and Wuepper, K. D.: Activation of Hageman factor in solid and fluid phases. A critical role of kallikrein. J. Exp. Med., 138: 1564 (1973).

6. Cochrane, G. C. and Wuepper, K. D.: The first component of the kinin-forming system in human and rabbit plasma. Its relationship to clotting factor XII (Hageman factor). J. Exp. Med., 134: 986 (1971).

7. Colman, R. W., Mason, J. W., and Sherry, S.: The kallikreinogen-kallikrein enzyme system of human plasma. Ann. Int. Med., 71: 763 (1969).

8. Colman, R. W., Mattler, L., and Sherry, S.: Studies on the prekallikrein (kallikreinogen)-kallikrein enzyme system of human plasma. II. Evidence relating the kaolin-activated arginine esterase to plasma kallikrein. J. Clin. Invest., 48: 23 (1969).

9. Davies, G. E., Holman, G., Johnston, T. P., and Lowe, J. S.: Studies on kallikrein: Failure of some anti-inflammatory drugs to affect release of kinin. Brit. J. Pharmacol., 28: 212 (1966).

10. Dixon, F. J., Wilson, C. B., and Marquardt, H.: Experimental immunologic glomerulonephritis. In: J. Hamburger, J. Crosnier, and M. H. Maxwell: Advances in Nephrology (Year Book Medical Publishers, Chicago, 1971).

11. Drummond, K. N., Michael, A. F., Good, R. A., and Vernier, R. L.: The nephrotic syndrome of childhood: Immunologic, clinical and pathologic correlations. J. Clin. Invest., 45: 620 (1966).

12. Duffy, J. L., Cinque, T., Grishman, E., and Churg, J.: Intraglomerular fibrin, platelet aggregation, and subendothelial deposits in lipoid nephrosis. J. Clin. Invest., 49: 251 (1970).

13. Eisen, V., Greenbaum, L., and Lewis, G. P.: Kinins and antiinflammatory steroids. Brit. J. Pharmacol., 34: 169 (1968).

14. Farqhuar, M. G., and Palade, G. E.: Glomerular permeability. II. Ferritin transfer across the glomerular capillary wall in nephrotic rats. J. Exp. Med., I14: 699 (1961).

15. Fredrickson, D. S., Levy R. I., and Lees, R. S.: Fat transport in lipoproteins-an integrated approach to mechanisms and disorders. New Engl. J. Med., 276: 273 (1967).

16. Gerber, M. A., and Paronetto, F.: IgE in glomeruli of patients with nephrotic syndrome. Lancet, $i: 1097$ (197l).

17. Gigli, I., Mason, J. W., Colman, R. W., and Austen, K. F.: Interaction of plasma kallikrein with the $\mathrm{C}_{1}$ inhibitor. J. Immunol., 104: 574 (1970)

18. Habib, R, and Kleinknecht, C.: The primary nephrotic syndrome of childhood. Pathol. Ann. 6: 417 (1971).

19. Harpel, P. C.: Human plasma alpha-2 macroglobulin. An inhibitor of plasma kallikrein. J. Exp. Med., 132: 329 (1970)

20. Harpel, P. C.: Studies on the interaction between collagen and a plasma kallikrein-like activity. Evidence for a surface-active enzyme system. J. Clin. Invest., 51: 1813 (1972).

21. Honig, G. R., and Lindley, A.: Deficiency of Hageman factor (Factor XII) in patients with the nephrotic syndrome. J. Pediat., 78: 633 (1971).

22. Hoyer, J. R., Raij, L., Vernier, R. L., Simmons, R. L., Najarian, J. S., and
Michael, A. F.: Recurrence of idiopathic nephrotic syndrome after renal transplantation. Lancet, ii: 343 (1972).

23. Hunsicker, L. G., Wintroub, B. U., and Austen, K. F.: Humoral amplification systems in inflammation. In: F. H. Bach and R. A. Good: Clinical Immunobiology (Academic Press, New York, 1972).

24. Lange, L. G., III, Carvalho, A., Bagdasarian, A., Lahiri, B., and Colman, R. W.: Activation of Hageman factor in the nephrotic syndrome. Amer. J. Med., 56: 565 (1974).

25. Lewis, E. J., Kallen, R. J., and Rowe, D. S.: Glomerular localisation of IgE in lipoid nephrosis. Lancet, $i$ : 1395 (1973).

26. Lewis, G. P.: Kinins in inflammation and tissue injury. In: E. G. Erdös: Handbook of Experimental Pharmacology, Vol. 25 (Springer-Verlag, New York, 1970).

27. Lieberman, E., Heuser, E., Gilchrist, G. S., Donnell, G. N., and Landing, B. H.: Thrombosis, nephrosis, and corticosteroid therapy. J. Pediat., 73: 320 (1968).

28. Lines, D. R.: Selectivity of proteinuria in childhood nephrotic syndrome. Arch. Dis. Childhood, 44: 461 (1969).

29. Roy, L. P., Westberg, N. G., and Michael, A. F.: Nephrotic syndrome-no evidence for a role for IgE. Clin. Exp. Immunol., 13: 553 (1973).

30. Revak, S. D., Cochrane, C. G., Johnston, A. R., and Hugli, T. E.: Structural changes accompanying enzymatic activation of human Hageman factor. $J$. Clin. Invest., 54: 619 (1974).

31. Scheinman, J. I., and Stiehm, E. R.: Fibrinolytic studies in the nephrotic syndrome. Pediat. Res., 5: 206 (1971).

32. Snedecor, G. W., and Cochran, W. G.: Statistical Methods, Ed. 6 (lowa State University Press, Ames, Iowa, 1967).

33. Uttley, W. S., Maxwell, H., and Cash, J. D.: Fibrin/fibrinogen degradation products in children with renal disease. Arch. Dis. Childhood, 49: 137 (1974).

34. Weiss, A. S., Gallin, J. I., and Kaplan, A. P.: Fletcher factor deficiency: A diminished rate of Hageman factor activation caused by absence of prekallikrein with abnormalities of coagulation, fibrinolysis, chemotactic activity, and kinin generation. J. Clin. Invest., 53: 622 (1974).

35. Wilner, G. D. Nossel, H. L., and LeRoy, E. C.: Activation of Hageman factor by collagen. J. Clin. Invest., 47: 2608 (1968).

36. Wong, P., Colman, R. W., Talamo, R. C., and Babior, B. M.: Kallikreinbradykinin system in chronic alcoholic liver disease. Ann. Int. Med., 77: 205 (1972).

37. Cyclo Chemical, Los Angeles, Calif.

38. Behring Diagnostics, Somerville, N.J.

39. A preliminary report of these findings was presented at the Midwest Society for Pediatric Research, November 8, 1973, Pittsburgh, Pennsylvania, and the 1974 Annual Meeting of The American Pediatric Society-The Society for Pediatric Research (Pediat. Res., 8: 183 (1974)).

40. Dr. S.-K. Lee was supported in part by the Nephrosis Research Foundation and a Fellowship Award from the Kidney Foundation of Illinois.

41. Requests for reprints should be addressed to: R. J. Kallen, M.D., La RabidaUniversity of Chicago Institute East 65th St. at Lake Michigan Chicago, Ill. 60649 (USA)

42. Accepted for publication April 28, 1975.
Branched chain $\alpha$-ketoacids

fibroblasts

$\alpha$-ketoacid decarboxylation maple syrup urine disease residual decarboxylation activity

\title{
Maple Syrup Urine Disease: Analysis of Branched Chain Ketoacid Decarboxylation in Cultured Fibroblasts
}

\author{
U. WENDEL, ${ }^{(47)}$ H. WENTRUP, AND H. W. RÜDIGER \\ Division of Cytogenetics and Clinical Genetics, Department of Human Genetics, University of Hamburg, Hamburg, \\ West Germany
}

Extract

Kinetic data are presented for the decarboxylation of branched chain $\alpha$-ketoacids (BCKA) by intact human fibroblasts. Cultured cells of normal individuals and nine patients with different clinical pictures of maple syrup urine disease (MSUD) are studied with both $\alpha$-ketoisocaproic acid (2-oxo-4-methylpentanoic acid (KIC)) and $\alpha$-ketoisovaleric acid (2-oxo-3-methylbutanoic acid (KIVA)) 
as substrates. One normal cell strain and one patient cell strain is analyzed with $\alpha$-keto- $\beta$-methyl- $n$-valeric acid (2-oxo-3-methylpentanoic acid (MEVA)) as a substrate.

A biphasic degradation kinetic for each BCKA is obtained for normal control subjects. The component with higher substrate affinity is affected in MSUD: for KIC the normally hyperbolic substrate curve is changed to sigmoid shape, for KIVA and MEVA as substrates this component is not detectable at all. Considering qualitative aspects of the BCKA decarboxylation kinetics intact fibroblasts yield the same results as our recent studies with the decarboxylase moieties of partially purified kidney BCKA dehydrogenase of normal individuals and one patient with classic MSUD (27).

The decarboxylation velocities for normal and patient fibroblasts with one exception differ widely at low but not at high substrate concentrations of BCKA. To get meaningful data on the residual substrate degradation activities with intact fibroblasts of different phenotypes of MSUD physiologically low substrate concentrations are recquired in the assay.

\section{Speculation}

Kinetic studies of the decarboxylation reaction for branched chain $\alpha$-ketoacids with fibroblasts of patients suffering from maple syrup urine disease could yield information about the type of biochemical abnormality in MSUD.

Maple syrup urine disease is an autosomal recessive disorder of man that is biochemically characterized by defective oxidative decarboxylation of the branched chain $\alpha$-ketoacids, $\alpha$-ketoisocaproic acid, $\alpha$-ketoisovaleric acid, $\alpha$-keto- $\beta$-methyl- $n$-valeric acid, derived from the amino acids, leucine, valine, and isoleucine, respectively. This metabolic step involves three specific enzyme proteins which form a multienzyme complex resembling the well known multienzyme complexes of pyruvate and $\alpha$-ketoglutarate dehydrogenase $(13,23-25)$. The three enzymes calalyze the following consecutive reactions: (1) decarboxylation of the ketoacids to an active aldehyde by thiamine pyrosphosphate containing decarboxylase, (2) oxidation of the active aldehyde by lipoic acid containing transacylase and transfer of the acyl group to coenzyme A-SH, (3) reoxidation of the protein-bound cofactor lipoic acid by the flavine enzyme lipoamide oxidoreductase in the presence of $\mathrm{NAD}^{+}$. The latter enzyme is a constituent of the pyruvate and $\alpha$-ketoglutarate dehydrogenase complex which were shown repeatedly to be intact in MSUD. Probably more than one specific dehydrogenase is responsible for the degradation of the three BCKA $(3,13,19)$.

Phenotypic heterogeneity of MSUD has been described; an intermittent type (5), intermediate types $(12,29)$, and a thiamineresponsive type (30) were distinguished from the classic type which has the most severe clinical symptoms (7, 22). Quantitative decarboxylation studies with cultured fibroblasts using radiolabeled branched chain amino acids (BCAA) as substrates revealed activities below the $2 \%$ level of normal in the case of classic MSUD and somewhat higher values for variant types $(6,29)$. Besides the thiamine responsiveness and differences in enzyme activity qualitative differences between normal and mutant BCKA dehydrogenase complexes were obtained in case of classic MSUD. The BCKA decarboxylation of broken MSUD fibroblasts was shown to be resistant to cofactor stimulation in contrast to normal cells $(9,10)$. Previously an altered decarboxylation moiety of the renal enzyme complex was demonstrated for a neonate who had died from classic MSUD (27). In most studies broken cells or solubilized enzymes were used for the respective assay. In view of the complex structural and cofactor requirements of ketoacid dehydrogenase complexes and eventual enzyme-regulating mechanisms, as in case of pyruvate dehydrogenase $(17,24)$, optimal physiologic conditions are hardly to be expected in all of those assays. Extensive loss of enzyme activity accompanies the solubilization procedures $(6,36)$.

Tests with viable cells instead provide an opportunity to approximate in the test system in vivo conditions as closely as possible.
Whereas phenomena like membrane transport and intracellular pools and compartmentation of branched chain keto acids are barely understood at present, it is nevertheless generally accepted that any defect in BCKA decarboxylation, as observed in MSUD, is due to a genetically determined defect of BCKA dehydrogenase(s) (31). Accordingly, with the current state of knowledge in mind, we considered it worthwhile to try to obtain kinetic data for BCKA decarboxylation in intact normal and MSUD fibroblasts. Any clear-cut differences between normal and patient cell lines should at least throw light on abnormal mechanisms operating in vivo and eventually yield hints as to the type of biochemical abnormality involved in different MSUD mutants.

\section{MATERIALS AND METHODS}

\section{CELLULAR MATERIAL}

The fibroblasts were grown from skin biopsies in different subcultures. Five cell strains $(C W, I K, W W, H R, T K)$ were taken from individuals not affected with matabolic diseases, nine cell strains from patients with differences in severity of the clinical picture of MSUD. $K Q, H G, S S$, and $A R$ are patients who are doing well with a semisynthetic or low protein diet. Four patients $(K C, A G, S L, C C$ ) were more severely affected or had died. The cell strain $K G$ is derived after prenatal diagnosis from an aborted fetus at 21 weeks of gestation homozygous for MSUD. Clinical data of the patients $K C, H G, K Q, K G$, and $S S$ have been published $(6,14,16,28,35)$.

\section{DECARBOXYLATION ASSAY}

Sodium salts of KIC, KIVA, and MEVA were bought from Sigma, St. Louis; pyruvate from Boehringer, Mannheim. The corresponding $1{ }^{14} \mathrm{C}$-labeled acids were prepared from DL-[1$\left.{ }^{14} \mathrm{C}\right]$ leucine, DL- $\left[1-{ }^{14} \mathrm{C}\right]$ valine $(39)$ and $\mathrm{L}-\left[1-{ }^{14} \mathrm{C}\right]$ isoleucine $(40)$ as described previously (26). L- $\left[-{ }^{14} \mathrm{C}\right]$ pyruvate was bought from the Radiochemical Centre.

The BCKA decarboxylation assay with fibroblasts in monolayer was performed as described previously (37) with modifications ( $I$ ) to to keep the assay system free of BCAA except for cellular contents, and (2) to obtain a constant $\mathrm{pH}$ of 6.9 . Fetal calf serum (FCS (41)), which was added to the test system for nutritional requirements of the cells, was passed through a Sepahdex G-10 column equilibrated with phosphate-buffered saline (PBS (42)) and $4 \mathrm{~g}$ glucose were added per liter. All assay constituents were adjusted to $\mathrm{pH} 6.9$ with $20 \mathrm{mM} \mathrm{N}$-2-hydroxyethylpiperazine propamine sulfonic acid (Hepes (42)) and $\mathrm{NaOH}$. The unlabeled keto acids were dissolved in PBS buffered with HEPES, the labeled ones were adjusted to $\mathrm{pH} 6.9$ before use and diluted to 0.5 $\mathrm{mM}$ with HEPES-buffered PBS. Specific radioactivity was 58 $\mathrm{mCi} / \mathrm{mmol}$ for $\mathrm{KIC}, 37.5 \mathrm{mCi} / \mathrm{mmol}$ for $\mathrm{KIVA}, 24 \mathrm{mCi} / \mathrm{mmol}$ for $\mathrm{MEVA}$, and $13.1 \mathrm{mCi} / \mathrm{mmol}$ for pyruvate. In the toluene scintillation counting system the employed counting efficiency was $82 \%$.

The medium of the cellular monolayer grown in a microtiter plate (Cooke type, 96 wells) was replaced by a freshly prepared reaction mixture composed of buffered gel-filtered FCS and HEPES-buffered PBS $(2: 8 ; \mathrm{v} / \mathrm{v})$ containing varying amounts of radiolabeled and unlabeled ketoacids. The ${ }^{14} \mathrm{CO}_{2}$ that evolved during incubation in a moist atmosphere at $37^{\circ}$ was trapped by alkaline glass fiber platelets, covering the wells. Kctoacid decarboxylation by fibroblasts was linear over $4 \mathrm{hr}$ of incubation (37).

KIC and KIVA were used as substrates in a range between $1 \times$ $10^{-5}$ and $1.605 \times 10^{-2} \mathrm{M}$. For concentrations below $5 \times 10^{-5} \mathrm{M}(5$ $\mathrm{nmol} /$ assay), pure radiolabeled ketoacids were applied, for higher concentrations $5 \mathrm{nmol} \neq 5 \%$ labeled acid were combined constantly with varying amounts of the corresponding unlabeled substance. Reaction velocities (picomoles of $\mathrm{CO}_{2}$ per microgram of cell protein in $4 \mathrm{hr}$ ) were calculated from the ${ }^{14} \mathrm{CO}_{2}$ actually measured using the ratio of labeled and unlabeled substrate in each assay. In the case of labeled MEVA the unknown ratio of the 1 and 
$\mathrm{d}$ isomer (the latter seems to serve as a substrate $(19,20)$ ) did not permit combination of radiolabeled and unlabeled substances. For economic reasons a limited number of tests with MEVA as a substrate were made applying pure radioactive substrate up to 1.2 $\times 10^{-3} \mathrm{M}$ to one normal $(H R)$ and one MSUD cell strain $(C C)$.

Wells containing reaction medium without cells served as reagent blanks in order to estimate the spontaneous decomposition of the BCKA under assay conditions. Blanks typically exhibit about $850 \mathrm{cpm}$ for KIC and 550-970 cpm for KIVA (depending on the lot of ketoacid preparation) at a concentration of $5 \times 10^{-5} \mathrm{M}$ of pure radioactive substrate. These values decreased to about 440 $\mathrm{cpm}$ for KIC and to $230-550 \mathrm{cpm}$ for KIVA when $5 \times 10^{-5} \mathrm{M}$ radioactive and $1.6 \times 10^{-2} \mathrm{M}$ unlabeled substrate were present in the reaction medium. The blank for MEVA was $280 \mathrm{cpm}(5 \times$ $\left.10^{-5} \mathrm{M}\right)$ and increased to $5,000 \mathrm{cpm}\left(1.2 \times 10^{-3} \mathrm{M}\right.$ of pure radioactive substrate).

Cell strains of normal individuals evolved maximally 12,000 $13,000 \mathrm{cpm}$ and $6,100-16,800 \mathrm{cpm}$ of ${ }^{14} \mathrm{CO}_{2}$ above the blank for KIC and KIVA, respectively. At the highest substrate concentration employed the differences were $380-430 \mathrm{cpm}$ for KIC and $350-520 \mathrm{cpm}$ for KIVA. Different patient cell strains in the assay evolved maximally 1,360 -5,200 cpm (KIC) and 150 - 1,300 cpm (KIVA) of ${ }^{14} \mathrm{CO}_{2}$ above the blank and at the highest substrate concentration 140-450 cpm for KIC and 50-390 cpm for KIVA.

Cell protein was estimated as described previously (37). Decarboxylation in normal controls was proportional to cell protein in the range of $2-25 \mu \mathrm{g} /$ assay. About $4 \times 10^{4}$ cells corresponding to $15-20 \mu \mathrm{g}$ cell protein were needed for each assay. Each single symbol in the figures (Figs. 1-4) represents the mean of four parallel determinations corrected for the individual blank.

\section{CALCULATIONS}

The experimental data were plotted either as decarboxylation rate versus substrate concentration (Michaelis-Menten plot) or as $\log v / \mathrm{V}_{\max }-\mathrm{v}$ versus $\log \mathrm{S}$ (Hill plot). In Hill plots values for the half-saturation substrate concentration $(\mathrm{S})_{0.5}$ as well as the Hill coefficients $n_{\mathrm{H}}$ (1) were taken from regression lines calculated according to the least squares method. The $V_{\max }$ values were estimated by a graphic method plotting $S / v$ versus $S$. Substrate concentrations beyond $1.6 \times 10^{-2} \mathrm{M}$ obtained by further addition of unlabeled substance would have ton much diluted the labeled compound actually measured and would have caused large errors in rate calculations.

Under the assumption that experimentally obtained substrate curves were composed of two kinetic compounds, a computerized iterative program based on the equation

$$
\mathrm{V}=\frac{\mathrm{V}_{\text {max }_{1}}}{1+\left(\frac{\left(\mathrm{S}_{1}\right)_{0.5}}{\mathrm{~S}}\right)^{n_{1}}}+\frac{\mathrm{V}_{\text {max }_{2}}}{1+\left(\frac{\left(\mathrm{S}_{2}\right)_{0.5}}{\mathrm{~S}}\right)^{n_{2}}}
$$

was applied to resolve the kinetics (43).

\section{RESULTS}

\section{KIC AS SUBSTRATE}

The KIC decarboxylation by fibroblasts from MSUD patients and normal control subjects follows biphasic kinetics in a $\mathrm{Mi}$ chaelis-Menten plot (Fig. la). One component is approximately saturated at $15 \times 10^{-4} \mathrm{M} \mathrm{KIC}$ and exhibits $(\mathrm{S})_{0.5}$ values on the order of $10^{-4} \mathrm{M}$. The other component is saturated at more than 10 times higher concentrations; however, substrate saturation is not obtained in the experiments. Figure $2 a$ shows the substrate curves on an extended scale between 0.1 and $15 \times 10^{-4} \mathrm{M} \mathrm{KIC}$. The curves are sigmoidal in shape for nine cell strains derived from MSUD patients. In contrast, hyperbolic kinetics are observed with normal control subjects. $V_{\max }$ of the component with high substrate affinity is not altered essentially in MSUD.

The low affinity KIC decarboxylation component is sigmoidal in shape for both normal and MSUD fibroblasts. $V_{\max }$ of that component is not altered in eight patients; however, it is greatly reduced for one $(A G)$, as shown in Figure $1 a$. In Hill plots MSUD fibroblasts differ from normal controls only in the slope of the lower sections (Fig. 3a).

\section{KIVA AS SUBSTRATE}

Two kinetic components are also shown for normal cellular KIVA decarboxylation (Fig. $1 b$ ). The component with higher substrate affinity is hyperbolically shaped and has characteristics similar to the corresponding decarboxylation component with KIC as a substrate; $(\mathrm{S})_{0.5}$ is on the order of $10^{-4} \mathrm{M}$ KIVA (Fig. $2 b$ ).

The low affinity KIVA decarboxylation component has twice the $\mathrm{V}_{\max }$ of KIC as a substrate and is already very active at KIVA concentrations as low as $2 \times 10^{-4} \mathrm{M}$. Similar values for $V_{\max }$ are revealed for this component in normal and MSUD cell strains; however, $\mathrm{V}_{\max }$ for the cell strain $A G$ is greatly reduced, as with KIC as a substrate (Fig. $1 b$ ). Substrate saturation is not obtained in the experiments. The substrate curves are slightly sigmoidal in shape. Kinetics of cell strains from eight patients do not contain the high affinity component when tested with KIVA as a substrate: only a pure sigmoidal kinetic is registered in each case. Consequently, Hill plots are straight lines in contrast to those for normal controls (Fig. 3b)

\section{MEVA AS SUBSTRATE}

MEVA decarboxylation was measured in one normal cell strain $(H R)$ and one cell strain from a patient $(C C)$ with substrate concentrations from 0.25 to $12 \times 10^{-4} \mathrm{M}$ (Fig. 4). It resembles the decarboxylation of KIVA. Although normal cells show biphasic kinetic data (the component with high substrate affinity is hyperbolic) the fibroblasts of patient $C C$ exhibit a single sigmoidshaped substrate curve with no signs of an approximate saturation at the tested substrate concentrations.

Kinetic data obtained with the three substrates are summarized in Table 1. The experimental substrate curves for control and MSUD fibroblasts with KIC and those for control fibroblasts with KIVA could be split by a computerized analysis into two additive and saturable kinetic components with different $(\mathrm{S})_{0.5}$ values. MSUD fibroblasts with KIVA as a substrate yielded high substrate affinity components with negligible low $V_{\max }$ values compared with those obtained for the low substrate affinity component.

In order to get comparable quantitative data on ketoacid decarboxylation activity in normal and MSUD cell strains, fibroblasts from the nine patients and fibroblasts from 21 normal individuals (without metabolic diseases) were tested at the same substrate concentration $\left(5 \times 10^{-5} \mathrm{M}\right.$ of labeled KIC and KIVA, respectively). The results are listed in Table 2 . The fibroblasts of the nine patients in our assay show residual degradation activities below $5 \%$ of the mean for normal controls. Only patient $S S$ has $7.8 \%$ of normal KIC and $5 \%$ of normal KIVA decarboxylation activity.

\section{DISCUSSION}

Although it is possible to measure the decarboxylase reaction of the BCKA dehydrogenase complex, pure enzyme kinetics cannot be obtained with intact fibroblasts since several distinct events preceed the enzymic substrate degradation. Cellular uptake of the ketoacids and transportation into the mitochondria as well as alteration of the intracellular substrate concentration by backtransamination to the animo acid analoge interfere with determination of enzyme kinetics. Furthermore, interactions of the consecutive enzymes within the BCKA dehydrogenase complex with the decarboxylating moieties cannot be excluded. We did not obtain data for the effects of cellular and mitochondrial transport, nor could we determine the cellular levels of endogenous BCKA. All substrate concentrations mentioned in our work refer to amounts of BCKA in the extracellular reaction mixture and not to 

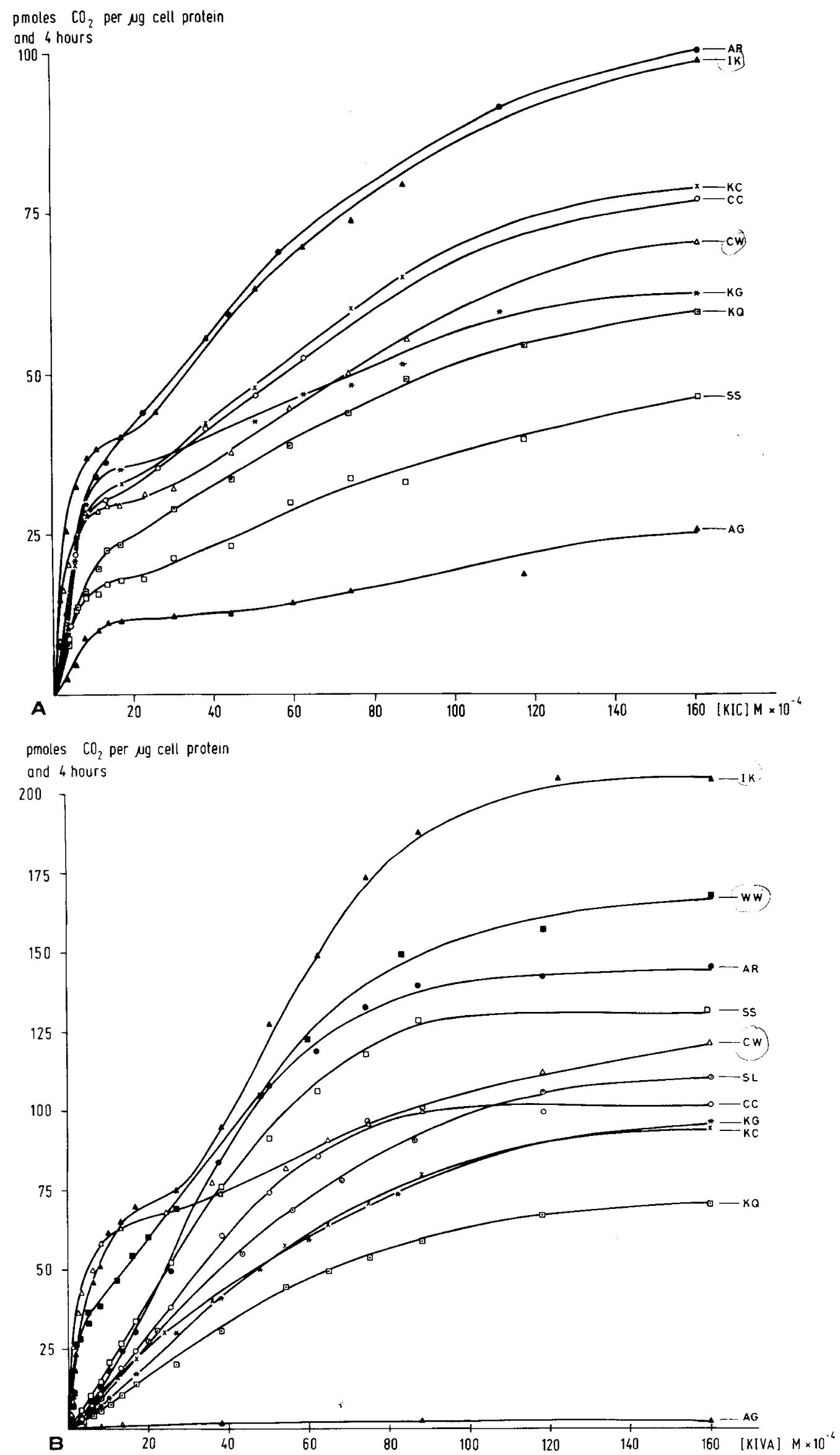

Fig. 1. Plots of the cellular decarboxylation rate (picomoles of $\mathrm{CO}_{2}$ per microgram of cell protein in $4 \mathrm{hr}$ ) versus extracellular substrate concentration. Data from two normal control subjects $(I K, C W)$ and seven maple syrup urine disease cell strains with $\alpha$-ketoisocaproic acid as a substrate $(a)$ and three normal control subjects $(I K, W W, C W)$ and eight maple syrup urine disease cell strains with $\alpha$-ketoisovaleric acid as a substrate $(b)$. 
pmoles $\quad \mathrm{CO}_{2}$ per $\mu \mathrm{g}$ cell protein

and 4 hours
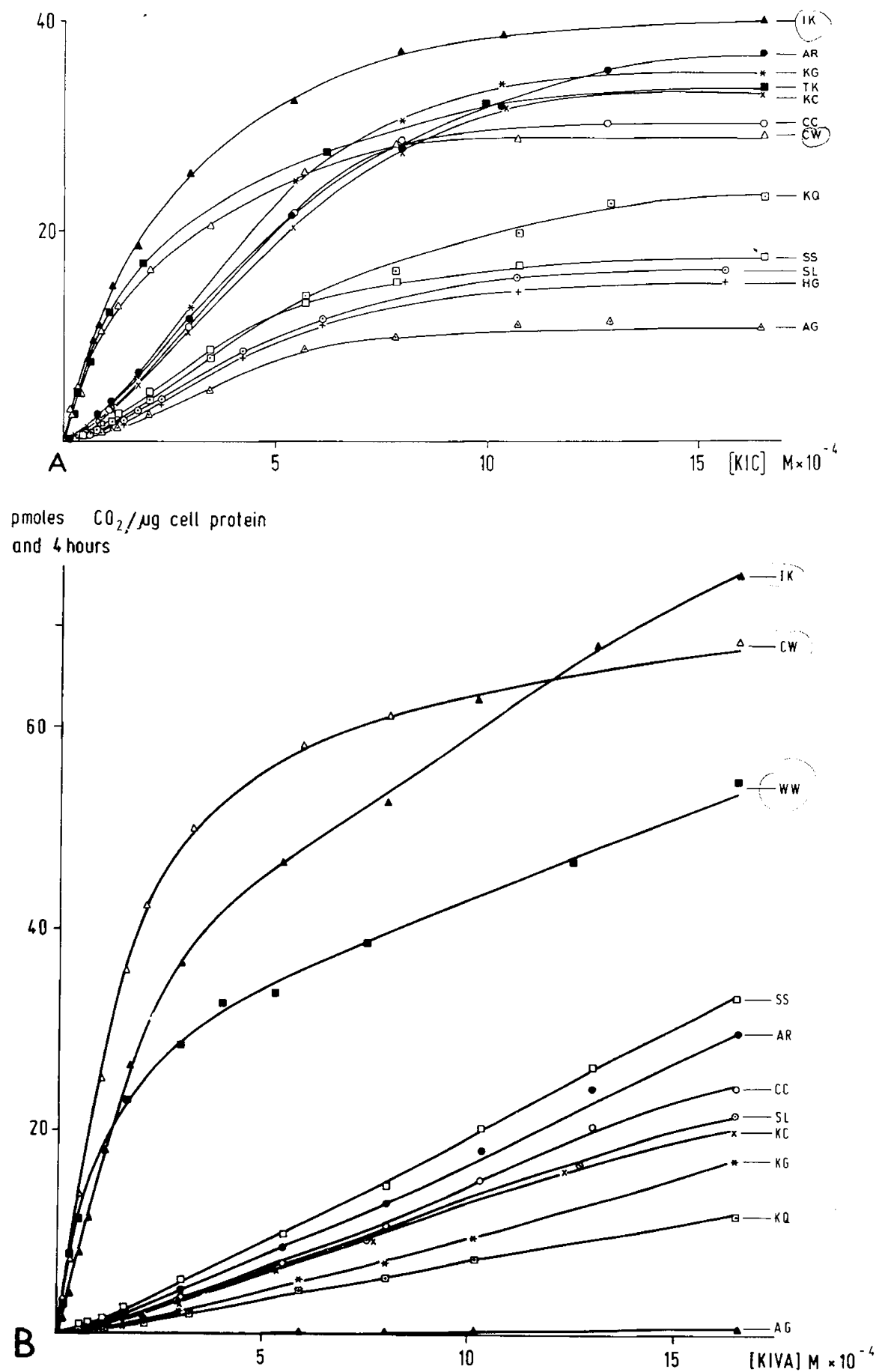

Fig. 2. Plots of Figure $1 a$ and $b$ on an extended scale between 0.1 and $15 \times 10^{-4} \mathrm{M}$ of substrate. Data from three normal control subjects ( $I K, T K, C W$ ) and nine maple syrup urine disease cell strains in the case of $\alpha$-ketoisocaproic acid $(K I C)(a)$ and three normal $(I K, W W, C W)$ and eight maple syrup urine disease cell strains in the case of $\alpha$-ketoisovaleric acid $(K I V A)(b)$.

their actual concentration at the intramitochondrial location of the decarboxylase.

Intact MSUD fibroblasts accumulate endogenous substrate during cell culturing. Since free amino acid concentrations in the culture medium (21) were as high as in plasma of MSUD patients under strict dietary control (18), maximally about $0.25 \times 10^{-6} \mathrm{~mol}$ endogenous substrate/assay couid be expected, a figure based on data recently published $(8,18)$. This amount appears not to be relevant for the calculation of the decarboxylation kinetics.

Transamination back to the corresponding amino acid might be an important route for removal of the BCKA in MSUD.
Lancaster et al. (18) concluded from their data for the BCAA and BCKA concentrations in plasma of MSUD patients that reverse transamination in these patients was very effective when BCKA concentrations did not exceed 10 -fold the normal. These in vivo findings leave open the possibility that efficient transamination and reverse transamination are produced by different and orga, 1 specific transaminases (18) and they are not conclusive for the present in vitro experiments with one uniform cell type only.

Since it is generally accepted that MSUD is caused by a deficient enzymic step of BCKA oxidation and no data exist to suggest a membrane or transportation defect in that disease, differences 

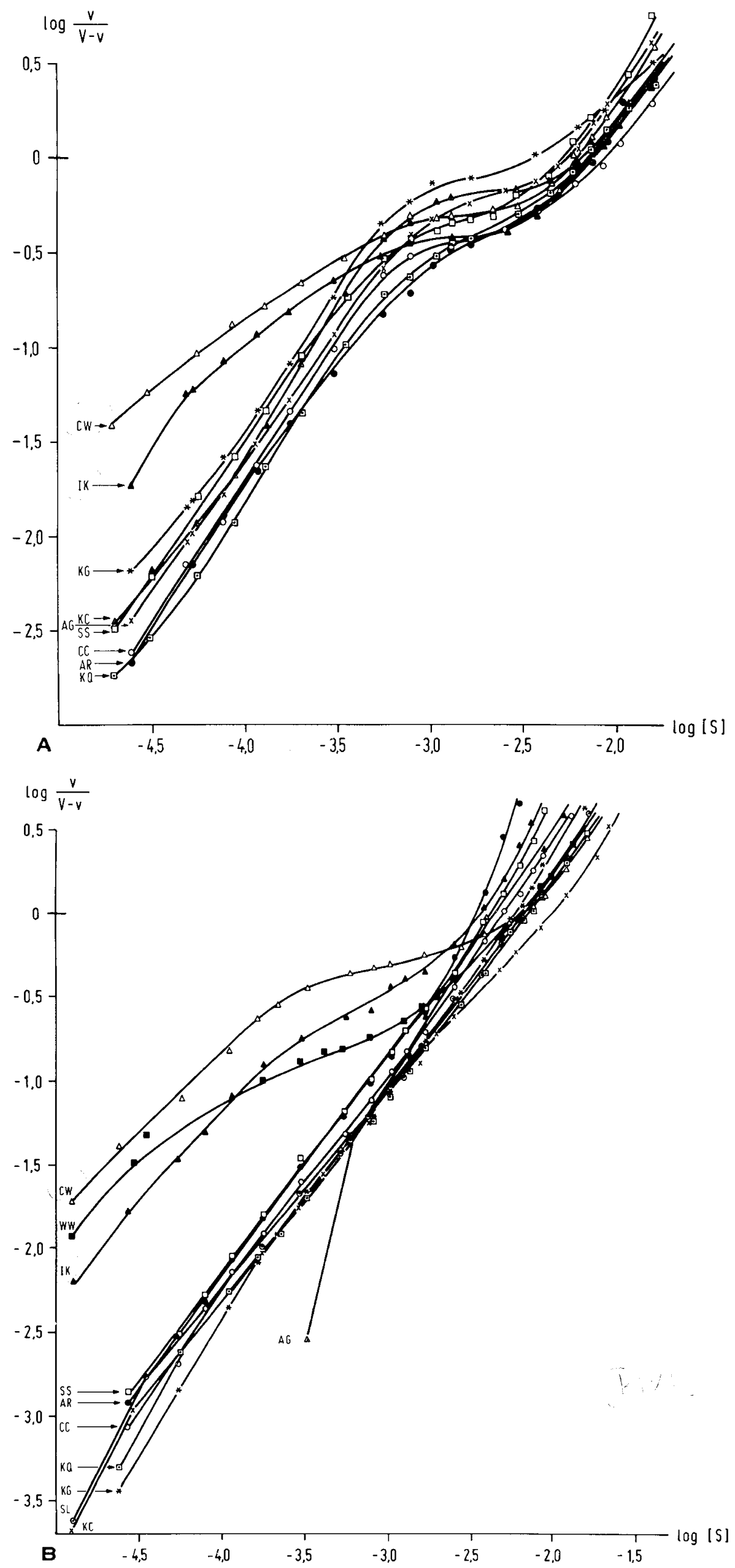

Fig. 3. Hill plots of $\alpha$-ketoiscaproic acid and $\alpha$-ketoisovaleric acid decarboxylation. Two normal controls $(C W, I K)$ and seven maple syrup urine disease eell strains for $\alpha$-ketoisocaproic acid as a substrate $(a)$ and three normal control subjects $(C W, W W, I K)$ and eight maple syrup urine disease cell strains 
in the decarboxylation kinetics between control and MSUD fibroblasts might well be interpreted as differences in enzymic reactions.

Our findings suggest strongly a biphasic decarboxylation reaction for the three BCKA in intact normal fibroblasts with a different substrate affinity for each component. All MSUD cell strains show altered components with respect to high substrate affinity, where they are relevant also for the BCKA metabolism at physiologic plasma substrate concentrations (KIC, $2.7 \times 10^{-6} \mathrm{M}$;

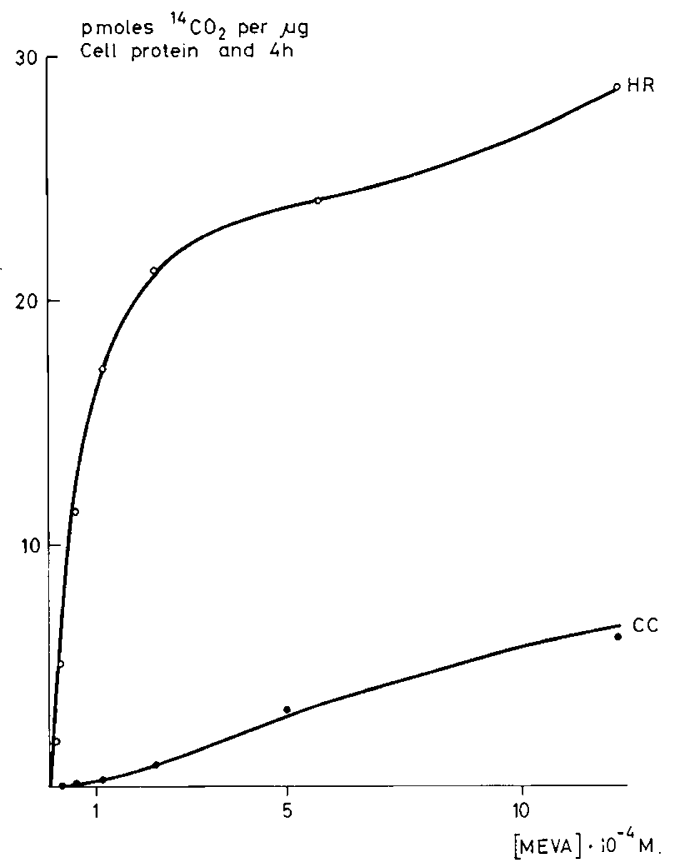

Fig. 4. Plots of decarboxylation rate versus extracellular substrate concentration for $\alpha$-keto- $\beta$-methyl- $n$-valeric acid $(M E V A)$ as a substrate for one normal control $(H R)$ and one maple syrup urine disease cell strain $(C C)$. The amounts of MEVA recorded on the abscissa indicate the total amount of the radiolabeled $d$ and 1 form per assay, composed on a constant but unknown ratio.
KIVA, $9.0 \times 10^{-6} \mathrm{M}$; MEVA, $\left.5.6 \times 10^{-6} \mathrm{M}(18)\right)$. The low affinity component of KIC and KIVA decarboxylation remains unchanged by the MSUD mutation with the exception of one cell strain.

Concerning the biphasic characteristics of the kinetics for KIVA and MEVA decarboxylation, identical results were obtained in a previous study (27) with partially purified renal BCKA dehydrogenase complex from normal control subjects and a child with classic MSUD who had died. The decarboxylase moiety of the BCKA dehydrogenase complex was investigated by utilizing the reduction of 2,6-dichloroindophenol in the presence of thiamine pyrophosphate as a cofactor in a cell and membrane free assay system. With 2,6-dichloroindophenol as an acceptor for active aldehyde, the transacylase reaction normally following the BCKA decarboxylation was eliminated. In that real enzyme assay decar-

Table 2. Branched chain $\alpha$-ketoacid decarboxvlation activity in fibroblasts at substrate concentrations of $.5 \times 10^{-4} \mathrm{M}$ $\left[1-{ }^{14} \mathrm{C}\right] \alpha$-ketoisocaproic acid $(\mathrm{KIC})$ and $\left[I-{ }^{14} \mathrm{C}\right] \alpha$-ketoisovaleric acid $(K I V A)^{1}$

\begin{tabular}{lcccc}
\hline & \multicolumn{2}{c}{ Activity against } & \multicolumn{2}{c}{$\begin{array}{c}\% \text { of } \\
\text { normal activity }\end{array}$} \\
\cline { 2 - 5 } \multicolumn{1}{c}{ Subjects } & KIC & KIVA & KIC & KIVA \\
\hline $\begin{array}{l}\text { Controls, } n=21 \\
\left(\mathrm{x} \pm \mathrm{s}_{\mathrm{D}}\right)\end{array}$ & $12.43 \pm 2.60$ & $14.85 \pm 4.0$ & 100 & 100 \\
Patients & & & & \\
$S S$ & 0.97 & 0.74 & 7.8 & 5.0 \\
$H G$ & 0.59 & 0.59 & 4.7 & 4.0 \\
$A R$ & 0.55 & 0.40 & 4.4 & 2.7 \\
$K Q$ & 0.51 & 0.39 & 4.1 & 2.6 \\
$C C$ & 0.52 & 0.38 & 4.2 & 2.5 \\
$K G$ & 0.62 & 0.52 & 4.9 & 3.5 \\
$S L$ & 0.46 & 0.29 & 3.7 & 2.0 \\
$K C$ & 0.23 & 0.29 & 1.8 & 2.0 \\
$A G$ & 0.23 & 0.10 & 1.8 & 0.7 \\
\hline
\end{tabular}

${ }^{1}$ Activities are expressed in picomoles of ${ }^{14} \mathrm{CO}_{2}$ evolved per microgram of cell protein in $4 \mathrm{hr}$. Means of four parallel assays (38).

Table 1. Kinetic data for branched chain $\alpha$-ketoacid decarboxylation in normal and maple syrup urine disease (MSUD) fibroblasts ${ }^{1}$

\begin{tabular}{|c|c|c|}
\hline Subjects & $\begin{array}{c}\text { High substrate affinity } \\
\text { decarboxylation component }\end{array}$ & $\begin{array}{c}\text { Low substrate affinity } \\
\text { decarboxylation component }\end{array}$ \\
\hline \multicolumn{3}{|l|}{$\mathrm{KIC}$} \\
\hline MSUD cell strains $(n=9)$ & $\begin{array}{l}\text { Sigmoid } \\
(\mathrm{S})_{0.5} \text { on the order of } 10^{-4} \mathrm{M} \text {; higher than } \\
\text { for normal controls } \\
\mathrm{V}_{\max } 15-50^{2}\end{array}$ & $\begin{array}{l}\text { Sigmoid } \\
(\mathrm{S})_{0.5} \text { on the order of } 10^{-3} \text { to } 10^{-2} \mathrm{M} \\
\mathrm{V}_{\max } 30-70^{2} \\
A G, \mathrm{~V}_{\max } \text { very low }\left(5.0^{2}\right)\end{array}$ \\
\hline \multicolumn{3}{|r|}{ 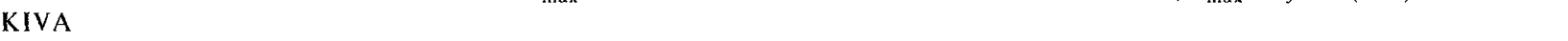 } \\
\hline Normal controls $(n=3)$ & $\begin{array}{l}\text { Hyperbolic } \\
\qquad(\mathrm{S})_{0.5} \text { on the order of } 10^{-4} \mathrm{M} \\
\mathrm{V}_{\max } 30-80^{2}\end{array}$ & $\begin{array}{l}\text { Sigmoid } \\
(\mathrm{S})_{0.5} \text { on the order of } 10^{-3} \text { to } 10^{-2} \mathrm{M} \\
V_{\max } 70-140^{2}\end{array}$ \\
\hline MSUD cell strains $(n=8)$ & Not detectable & $A G, \mathrm{~V}_{\max }$ very low $\left(5.0^{2}\right)$ \\
\hline \multicolumn{3}{|l|}{ MEVA } \\
\hline MSUD cell strain $(n=1)$ & Not detectable & \\
\hline
\end{tabular}

${ }^{1} \mathrm{KIC}$ : $\alpha$-ketoisocaproic acid; KIVA: $\alpha$-ketoisovaleric acid. The kinetic constants of both components were obtained by graphic methods. Computerized evaluation with 20 sets of experimental values for each cell strain did not yield more exact data. These are not real enzyme constants, since events as cellular uptake of the substrate and transportation into the mitochondria will influence such results.

${ }^{2}$ Picomoles of $\mathrm{CO}_{2}$ per microgram of cell protein in $4 \mathrm{hr}$. 
boxylase reaction for normal individuals followed biphasic kinetics with KIVA and MEVA as substrates and the high substrate affinity component was absent in classic MSUD. Because of very low activity in this assay system no sufficient data for KIC decarboxylation could then be obtained. Regrettably, fibroblasts of that special MSUD case were not at our disposal for direct comparison.

Our experiments do not elucidate whether both BCKA decarboxylation components of control fibroblasts represent two different specific decarboxylase systems. The very low substrate affinity of one decarboxylation component could also be caused by a decarboxylating enzyme with different ketoacid specificity that may exhibit some activity with the branched chain compounds. Unspecific reaction of pyruvate decarboxylase could be excluded from the uniform hyperbolic kinetics obtained with $\left[1-{ }^{14} \mathrm{C}\right]$ pyruvate as a substrate for normal and MSUD cell strains, among which was $A G$. Otherwise at least some variation in the kinetics would have been suspected for $A G$ as in the case of defective pyruvate decarboxylase (2) under the same assay conditions (34).

Biphasic substrate saturation curves can also indicate multiple forms of an enzyme under assay conditions as it was assumed for the phenylalanine hydroxylase (15) or several interacting substrate binding sites on an enzyme molecule $(11,32)$. Biphasic Hill plots are described for yeast pyruvate dehydrogenase (33). The composition of mammalian pyruvate decarboxylase moieties out of two pairs of two different polypeptide chains as well as regulation of enzyme activity by different metabolities are established (17). In analogy, interacting substrate binding sites were proposed as a possible basis also for the biphasic BCKA decarboxylase kinetics obtained in the 2,6-dichloroindophenol test (19).

The fact that decarboxylation was reduced for all three BCKA in the case of MSUD analyzed up to now may indicate the presence of a special subunit common to the dehydrogenase complex for each BCKA (4). The present results support the thesis that a mutation in the gene controlling the synthesis of a common subunit of the enzyme complex may lead to MSUD. Within these bounds the special position of patient $A G$ is obvious. Up to now there have been no indications for a mutation in a specific subunit leading to an altered decarboxylation of one BCKA only. Eventually those defects pass clinically unrecognized (19).

Within the group of nine MSUD cell strains we obtained strikingly similar qualitative alterations of the kinetics for BCKA decarboxylation. Only small differences in the residual BCKA degradation activity were measured at $5 \times 10^{-5} \mathrm{M}$ substrate concentration, which is slightly above the normal serum concentration of these substances (18). Those differences correlate to some extent with the phenotypic expression of the disease. From our results, however, we conclude that the residual decarboxylation activity of MSUD fibroblasts observed with only one substrate concentration is not sufficient to explain the marked differences in clinical course of the patients and cannot be the basis for prognostic and therapeutic considerations as proposed (6). The kinetic patterns indicate that these estimations are inappropriate in MSUD because the residual decarboxylation activity of the MSUD fibroblasts will depend on the selected substrate concentration and will approach normal degradation levels with increasing substrate concentrations with KIC more than with KIVA. In the range of saturating substrate concentrations the differences between normal and MSUD cell strains except for $A G$ are within the interindividual variability of decarboxylation level for normal control subjects which is $25 \%$ in our assay. We obtained much lower residual degradation activities for variant forms of MSUD than other authors $(6,29)$ under similar conditions, because of the low substrate concentration $\left(5 \times 10^{-5} \mathrm{M}\right)$ used.

The data given in Table 1 present an obvious dilemma to a ready explanation of analytic chemical data from MSUD patients. Whereas KIC decarboxylation seems to be impaired least in MSUD according to our data, leucine as well as KIC are elevated most in plasma and urine of MSUD patients (31). Furthermore, leucine leads to rapid deterioration of the state of patients in loading studies. Much more work is required to link enzymic data with clinical and biochemical abnormalities in patients with MSUD.

\section{SUMMARY}

Differences in the kinetic characteristics of the branched chain $\alpha$-ketoacid decarboxylation of intact fibroblasts were evaluated for normal individuals and nine patients with maple syrup urine disease.

\section{REFERENCES AND NOTES}

1. Atkinson, D. E.: Regulation of enzyme activity. Ann. Rev. Biochem. 35: 85 (1966).

2. Blass, J. P., Avigan, J., and Uhlendorf, B. W.: A defect in pyruvate decarboxylase in a child with an intermittent movement disorder. J. Clin. Invest., 49: 423 (1970).

3. Connelly, J. L., Danner, D. J., and Bowden, J. A.: Branched chain $\alpha$-keto acid metabolism. J. Biol. Chem., 243: 1198 (1968).

4. Dancis, J., Hutzler, J., and Cox, R. P.: Enzyme defect in skin fibroblasts in intermittent branched chain ketonuria and in maple syrup urine disease. Biochem. Med., 2: 407 (1969).

5. Dancis, J., Hutzler, J., and Rokkones, T.: Intermittent branched chain ketonuria. Variant of maple-syrup-urine disease. New Engl. J. Med., 276: 84 (1967).

6. Dancis, J., Hutzler, J., Snyderman, S. E., and Cox, R. P.: Enzyme activity in classical and variant forms of maple syrup urine disease. J. Pediatr., 81: 312 (1972).

7. Dancis, J., Levitz, M., Miller, S., and Westall, R. G.: Maple syrup urine disease. Brit. Med. J., I: 91 (1959)

8. Dreyfus, P. M., and Prensky, A. L.: Further observations on the biochemical lesion in maple syrup urine disease. Nature, 214: 276 (1967).

9. Elsas, L. J., Pask, A. B., Wheeler, F. B., Perl, D. P., and Trusler, S.: Classical maple syrup urine disease: Cofactor ressistance. Metabolism, 21: 929 (1972).

10. Elsas, L. J., Priest, J. H., Wheeler, F. B., Danner, D. J., and Pask, B. A.: Maple syrup urine disease: Coenzyme function and prenatal monitoring. Metabolism, 23: 569 (1974).

11. Engel, P. C., and Ferdinand, W.: The significance of abrupt transitions in Lineweaver-Burk plots with particular reference to glutamate dehydrogenase. Biochem. J., 131: 97 (1973).

12. Fischer, M. H., and Gerristsen, T.: Biochemical studies on a variant of branched chain ketoaciduria in a 19-year-old female. Pediatrics, 48: 795 (1971).

13. Goedde, H. W., and Keller, W.: Metabolic pathways in maple syrup urine disease. In: W. L. Nyhan: Amino Acid Metabolism and Genetic Variation, p. 191 (McGraw-Hill Book Co., New York, 1967).

14. Hagge, W., Roland, W., Hironimi, G., and Dellenbusch, D.: A new variant of MSUD with diabetes melitus. Mayo Clin. Proc. (in press).

15. Kaufman, S.: The phenylalanine hydroxylating system from mammalian liver. Advan. Enzymol., 35: 245 (1971).

16. Koepp, P., Rybak, C., Ruidiger, H. W., and Wendel, U.: Maple syrup urine disease varient: Report on an infant. Z. Kinderheilk., I16: 177 (1974).

17. Koike, M., Hamada, M., Koike, K., Tanaka, N., Otsuka, K. I., and Suematsu, $T$.: Structure and action mechanism of $\alpha$-keto acid dehydrogenase multienzyme complex. In: Ogura, Tonomura, and Nakanura: Molecular Mechanism of Enzyme Action, p. 197 (University Park Press, Baltimore, 1973).

18. Lancaster, G., Mamer, O. A., and Scriver, C. R.: Branched chain alpha-keto acids isolated as oxime-derivates: Relationship to the corresponding hydroxy acids and amino acids in maple syrup urine disease. Metabolism, 23: 257 (1974).

19. Langenbeck. U.: Zur biochemischen Genetik der Ahornsirup krankheit (Habilitationsschrift, Göttingen, 1973).

20. Meister, A.: Studies on d- and $1-\alpha$-keto- $\beta$-methylvaleric acids. J. Biol. Chem., 190: 269 (1951).

21. Melancon, S. B., Tayco, J., and Nadler, H. L.: The free amino acid pool of cultivated human skin fibroblasts. Proc. Soc. Exp. Biol. Med., 141: 391 (1972).

22. Menkes, J. H., Hurst, P. L., and Craig, J. M.: New syndrome: Progressive familial infantile cerebral dysfunction associated with an unusual urinary substance. Pediatrics, 14: 462 (1954).

23. Namba, Y., Yoshizawa, K., Eijma, A., Hayashi, T., and Kaneda, T.: Coenzyme A- and nicotinamide adenine dinucleotide-dependent branched chain $\alpha$-keto acid dehydrogenase. J. Biol. Chem., 244: 4437 (1969).

24. Reed, L. J.: Pyruvate dehydrogenase complex. Current top. Cell Metab., 1: 233 (1969).

25. Rüdiger, H. W., Langenbeck, U., Brackertz, D., and Goedde, H. W.: Lipoic acid dependency of human branched chain $\alpha$-keto acid oxidase. Biochim. Biophys. Acta. 264: 220 (1972).

26. Ruidiger, H. W., Langenbeck, U., and Goedde, H. W.: A simplified method for the preparation of ${ }^{14} \mathrm{C}$-labeled branched-chain $\alpha$-oxo acids. Biochem. J., 126: 445 (1972).

27. Rüdiger, H. W., Langenbeck, U., Schulze-Schenking, M., Goedde, H. W., and Schuchmann, L.: Defective decarboxylase in branched chain ketoacid oxidase multienzyme complex in classic type of maple syrup urine disease. Humangenetik, 14: 257 (1972).

28. Schuchmann, L., Witt, J., Schulz, P., Schumacher, H., and Rüdiger, H. W. Multiple exchange transfusions as treatment during the acute period in maple 
syrup urine disease (MSUD). Helv. Paediat. Acta, 27: 449 (1972).

29. Schulman, J. D., Lustberg, T. J., Kennedy, J. L. Museles, M., and Seegmiller, J. E.: A new variant of maple syrup urine disease (branched chain ketoaciduria). Amer. J. Med., 49: 118 (1970).

30. Scriver, C. R., Mackenzie, S., Clow, C. L., and Delvin, E.: Thiamine-responsive maple syrup urine disease. Lancet, $i: 310$ (1972).

31. Scriver, C. R., and Rosenberg, L. E.: Branched chain amino acids. In: Amino Acid Metabolism and Its Disorders, p. 256 (Saunders, Philadelphia, 1973)

32. Seufert, D., Herlemann, E.-M., Albrecht, E., and Seubert, W.: Purification and properties of pyruvate carboxylase from rat liver. Hoppe-Seyler's Z. Physiol. Chem., 352: 459 (1971)

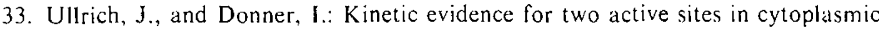
yeast pyruvate decarboxylase. Hoppe-Seyler's Z. Physiol. Chem., 35l: 1026 (1970)

34. Wendel, U.: Unpublished data.

35. Wendel, U., Rüdiger, H. W., Passarge, E., and Mikkelsen, M.: Maple syrup urine disease: Rapid prenatal diagnosis by enzyme assay. Humangenetik, 19. 127 (1973)

36. Wendel, U., Wentrup, H., and Ruidiger, H. W.: Unpublished data.

37. Wendel, U., Wöhler, W., Goedde, H. W., Langenbeck, U., Passarge, E., and Rüdiger, H. W.: Rapid diagnosis of maple syrup urine disease (branched chain ketoaciduria) by micro-enzyme assay in leukocytes and fibroblasts. Clin.
Chim Actid 45: 433 (1973).

38. Differences in the data for $H G$ and $S S$ from those in previous publications ( 16 $37)$ are due to a modified assay procedure. In contrast to the previous study the fetal calf serum was freed from amino acids by gel filtration.

39. Radiochemical Centre, Amersham, England.

40. Calatomic, Los Angeles, Calif.

41. Gibco, New York, N.Y.

42. Serva, Heidelberg, Germany,

43. The program for the mathematical analysis was written by Dr. Plesser Max-Planck-Institut für Ernährungs-physiologie, Dortmund, West Germany.

44. This paper is part of the M.D. thesis of $H$. Wentrup.

45. This research was supported in part by the Deutsche Forschungsgemeinschaft.

46. For the supply of skin or fibroblasts of the patients with MSUD we are indebted to Dr. C. Colombel, Lyon $(C C)$, Dr. L. Elsas, Atlanta $(K C)$, Dr. V. A. McKusick, Baltimore $(A R)$. Dr. H. J. Bremer, Düsseldorf $(S L)$, Dr. P. Koepp, Hamburg $(H G)$. Dr. W. Hagge and Dr. W. Roland, Stuttgart $(S S)$. Dr. L. Schuchmann, Freiburg $(K Q)$, and Dr. U. Wiesmann, Bern $(A G)$. The authors thank Dr. U. Langenbeck for critical discussion and Dr. E. Passarge for support in preparing the manuscript.

47. Requests for reprints should be addressed to: U. Wendel, M.D., University Children`s Hospital, D-4000 Düsseldorf, Moorenstr. 5, (West Germany)

48. Accepted for publication April 28, 1975.

\title{
Pyritinol Hydrochloride and Cognitive Functions: Influence on Children in Slow Learner Classes
}

\author{
Departments of Pediatrics, Neurology, and Clinical Pharmacology, University of Berne, Berne, Switzerland \\ U. WÄLTI, (37) M. KUENZLER, J. SCHILD, F. VASSELLA, E. PAVLINCOVA, J. BIRCHER, \\ AND N. HERSCHKOWITZ
}

\section{Extract}

Pyritinol-HCl was tested for its impact on the cognitive functions of children with learning disabilities. This study is a contribution to scientific discussion on the complicated methodologic problems in evaluating the clinical efficacy of psychopharmacologic agents.

Sixty-seven pupils of slow learner classes between the ages of 11 and 16 years were treated for 6 months with $300 \mathrm{mg}$ pyritinol$\mathrm{HCl} / \mathbf{2 4} \mathrm{hr}$ or placebo under strict double-blind conditions. Drug intake was stimulated and controlled by means of intense psychosocial interaction with the mothers of the subjects.

The dependence variables used to test medication effects were 22 parameters of cognitive performance measured in psychologic tests for perceptual and intellectual functions which were administered immediately before and after the medication phase.

First the gainscores before and after treatment with pyritinol or placebo within the 22 cognitive parameters were statistically compared. In addition, an analysis of covariance on the corrected results of the second test (treating the results of first testing as covariates) and a two group discriminant analysis for overall differences were performed.

None of the 22 parameters showed statistically significant treatment effects with respect to average performance ( $t$ (pyritinol - placebo $)=1.96$ to 1.31 ), neither could the two groups be separated by discriminant analysis (Hotelling's $T^{2}=\mathbf{3 5 . 4}, \mathrm{df}-$ 22 and $43, P=0.465$ ).

With respect to variability of gainscores, however, in four parameters there was a significantly higher variance in the pyritinol group $(F=1.85-2.33, P<0.05,<0.02$, respectively $)$. This fact may signify that pyritinol-HCl had different effects on different subjects. By means of prognostic stratification we therefore at- tempted to define objective criteria for a selection of subjects with probable positive treatment effects. None of the 15 tested criteria, such as body weight, age, perceptual handicaps, or reduced short term memory, IQ range, proved, however, to be critical for a prognosis of pyritinol effects within the present test population.

\section{Speculation}

Although there is no evidence for a general improvement of cognitive functions within the whole test population through treatment with pyritinol- $\mathrm{HCl}$, the results presented suggest slight medication effects in a positive as well as a negative direction for not as yet specifiable subpopulations. The definition of objective indications for the drug seems to be a major problem in testing psychopharmacologic agents.

In consideration of the increasing number of psychoactive drugs and the increasing tendency to administer them to children with behavioral and/or cognitive disorders, one could expect an increasing number of publications concerning behavioral and cognitive changes in children under the influence of psychopharmacologic agents. Nevertheless, an old complaint (6) on the lack of actual research in this field still holds true. In the last decade publications on this subject were extremely rare and some of the existing studies do not fulfill elementary methodologic criteria, as formulated by Taber (30), for clinical drug trials. At a first glance, these facts are surprising, especially with respect to the topic of drug influences on cognitive functions. Psychology has developed a great variety of cognitive tests which provide objective criteria for measuring drug influences. Several authors $(7,16,25,26)$, however, stress the considerable difficulties, such as patient-drug interactions, inter- 